\title{
Entre memória e história, filiação destruída, trauma, narrativa de vida e paixão por arquivos
}

\begin{abstract}
Resumo
Minha intervenção relata aspectos de uma pesquisa, ou antes, de um convívio com um grupo particular pessoas que foram crianças judias que permaneceram escondidas na Franca durante a Ocupação e que sobreviveram ao genocídio, e que eu encontrei 60 anos depois. Meu argumento vai apoiar-se na minha participação nas atividades da Associação pela memória do Comboio $\mathrm{Y}^{1}$, que elas criaram e cujas variadas atividades eu acompanhei, para depois realizar entrevistas com 16 participantes. Durante mais de quatro anos, acompanhei o grupo: as reuniões, as assembleias gerais, as viagens de comemoração no interior, em Paris e na Polônia, as exposições e os vários desenvolvimentos da associação criada pelo grupo. O grupo não se constituiu em razão de sua experiência dolorosa e singular de crianças judias escondidas na Franca durante a Ocupação, mas em nome da memória de seus pais deportados em julho de 1942, em sua maioria assassinados em Auschwitz. Perguntei-me o que estava em jogo no dinamismo dessas atitudes contemporâneas sobre traumas e desaparecimentos que datam mais de meio século, com o sentimento de que se reinstaurava uma possibilidade criativa de elaboração dos lutos e das perdas como autorizado ou legitimado pelo projeto de pesquisa sobre transmissão e uma paixão por arquivos.
\end{abstract}

Palavras-Chave: Crianças escondidas. Judeus. Deportação. Arquivos. Transmissão. Segunda guerra mundial.

\author{
Yoram Mouchenik \\ Professor de Psicologia Clinica \\ na Universidade Paris 13 - França. \\ yoram.mouchenik@free.fr
}

Tradução

Fernando Coelho

Mestre em Estudos da Tradução e doutorando em Linguística na

Universidade Federal

de Santa Catarina

zeffiretto@gmail.com

\section{Silvia Maria Fávero Arend}

Doutora em História.

Professora da Universidade do

Estado de Santa Catarina.

smfarend@gmail.com

\section{Para citar este artigo: \\ MOUCHENIK, Yoram. Entre memória e história, filiação destruída, trauma, narrativa de vida e paixão por arquivos. Revista Tempo e Argumento, Florianópolis, v. 5, n.9, jan./jun. 2013. p. 231 - 243.}

DOI: $10.5965 / 2175180305092013231$

http://dx.doi.org/10.5965/2175180305092013231

\footnotetext{
${ }^{1}$ Manteremos em anonimato o nome da associação e de seus participantes por respeito ao sigilo.
} 


\title{
Between memory and history, broken filiation, trauma, life story and passion for archives
}

\begin{abstract}
My paper describes some aspects of a research or rather a fellowship I conducted with a particular group of former Jewish children hidden in France during the occupation who survived the genocide and I met 60 years later. My purpose is based on my involvement with the Association for the memory convoy $Y$ they have created and I will follow the various activities and conduct interviews with 16 participants. For over four years, I will follow the group: meetings, general meetings, commemoration trips in province, in Paris and Poland, exhibitions and various developments of the association. The group didn't meet in the name of their singular and painful experience of Jewish children hidden in France during the WW II, but on behalf of the memory of their parents deported in July 1942 and mostly murdered in Auschwitz. I wondered what was at stake in the dynamism of those contemporary meeting about traumas and disappearances of more than half a century, with the feeling that recovering road and possible mourning were authorized or legitimized by their research project, transmission aims and passion for archives.
\end{abstract}

Keywords: Hidden Jewish children. Deportation. Archives. Transmission. World War II. 
Proponho-lhes uma reflexão comum acerca de um campo, o dos arquivos, do qual eu não sou especialista. Minha intervenção relata aspectos de uma pesquisa, ou antes, de um convívio (MOUCHENIK, 2004, 2006) com um grupo particular de pessoas que foram crianças judias que permaneceram escondidas durante a Ocupação e que sobreviveram ao genocídio, e que eu encontrei 60 anos depois. Meu argumento vai apoiar-se na minha participação nas atividades da Associação pela memória do Comboio Y, que elas criaram e cujas diferentes atividades eu acompanhei, para em seguida realizar entrevistas com 16 participantes. Durante mais de quatro anos, acompanhei o grupo: as reuniões, as assembleias gerais, as viagens de comemoração no interior, em Paris e na Polônia, as exposições e os vários desenvolvimentos da associação criada pelo grupo.

\section{O contexto}

O imediato pós-guerra ficou marcado pela inadmissível palavra dos judeus salvos dos campos de extermínio. Chamados deportados raciais, eles não são representados na ocasião das cerimônias de 11 de novembro de 1945, na Praça da Etoile (GANDINI, 1999, p.98); Primo Levi (1947/1987) não consegue publicar seu testemunho, Si c'est un homme. É preciso aguardar várias décadas para que um discurso sobre a colaboração, a deportação e o extermínio dos judeus da Europa encontre legitimidade no espaço público. Este silêncio certamente dá mostras de uma forma de congelamento da memória até os anos 1980. Na França, esta evolução recente está balizada certamente pelos processos Barbie (1985), Touvier (1994), Papon (1997), o filme Shoah, de Jacques Lanzman, em 1985, e o reconhecimento pelo ex-presidente da República, em 1995, da responsabilidade do Estado francês e de sua participação na solução final para os judeus da França. Este reconhecimento vem precedido pelo trabalho considerável de Serge Klarsfeld, não somente com Beate Klarsfeld como militantes antinazistas, cuja ação sobre a opinião pública e sobre o governo alemão obriga a julgar ex-nazistas, confortavelmente convertidos (processos de Colônia, etc.), mas também pela produção em 1978 do livro Mémorial des Juifs de France, baseado numa pesquisa arquivística na França, na Alemanha, 
na Polônia, etc., que recenseia o conjunto da deportação dos judeus da França, do qual a polícia francesa procedeu ao censo, às pilhagens e às prisões. Serge Klarsfeld, cujo pai foi preso e deportado quando ele tinha cinco anos, busca encontrar, nos arquivos o nome de todos os deportados judeus da França, com a data de sua deportação o número do comboio de partida da Franca e a data e o lugar de seu assassinato, quando conhecidos. Este livro, Le mémorial de la déportation des Juifs de France (KLARSFELD, 1978), livrosepultura, mas também arquivo de arquivos, provoca um verdadeiro choque com essas listas, esses nomes, essas datas, com o número de cada comboio, tendo para cada um deles um breve histórico, muitas vezes o primeiro epitáfio coletivo acessível à família. Esta publicação e esta materialização no espaço público são, muitas vezes, no momento, o primeiro passo para fazer um trabalho de luto possível. ${ }^{2} \mathrm{O}$ espaço do documento e do arquivo, como bem destacou Serge Klarsfeld para si mesmo: "O Memorial oferecia para a leitura o que eu tinha experimentado no local, em Auschwitz, quando encontrei o número de série do meu pai no registro de uma enfermaria, seguido por uma cruz. Naquele dia, minha busca acabou." (BOCHURBERG, 1997, p. 212)

Também no final dos anos 1980 houve a reativação dos trabalhos sobre a desapropriação dos judeus durante a Ocupação, as leis Juppé/Jospin sobre as reparações, a concessão de pensões, etc. O advento da possibilidade de uma memória socialmente reconhecida irá desencadear vários movimentos, associações, trabalhos, livros e também envolver esta demanda pelo arquivo e, por certo, uma paixão por arquivos.

O arquivo nos transporta ao passado, mas também sou da opinião de Derrida, que vê o arquivo como uma garantia para o futuro. Isto significa que o arquivo, que permite saber tanto quanto se pode, é um itinerário, um arquivo que pode conduzir a outro, um documento a outro. $\mathrm{O}$ arquivo é o vetor de uma temporalidade e de uma continuidade que guia a atenção de Derrida: "o arquivo sempre foi uma garantia. E como toda garantia, uma garantia de futuro." (Derrida, 1995, p. 37)

\footnotetext{
${ }^{2}$ Este projeto e a sua realização têm um alcance considerável para as famílias e descendentes dos judeus deportados da França. Simbolicamente, ele dá uma pista e inscreve no exterior de si o nome dos deportados ao figurá-los coletivamente e por comboios sucessivos, e gera a representação grupal retomada pelos descendentes.
} 


\section{A associação do Comboio Y e a demanda por arquivo}

O grupo composto por pessoas que foram crianças que permaneceram escondidas $^{3}$ na França durante a ocupação não se reuniu em função desta experiência comum, mas em nome de seus pais deportados para campos de extermínio num mesmo comboio ferroviário com mais de 900 pessoas, que eu denominarei aqui de Comboio $\mathrm{Y}, \mathrm{o}$ qual partiu de Loiret para Auschwitz em julho de 1942. É em nome deste destino comum que eles irão se encontrar com a ideia de que o fato de seus pais terem sido deportados juntos, e o mais das vezes terem sido assassinados juntos, Ihes confere um laço de parentesco. Os primeiros contatos, que serão responsáveis pela criação da futura associação, se estabeleceram quando um participante, Henri, colocou um anúncio no jornal à procura de descendentes de deportados em três comboios diferentes (deportados para serem assassinados): seu pai, sua mãe, seu irmão. Demorou três anos para que o grupo crescesse, e que, pela vontade e tenacidade de algumas pessoas, oitenta participantes se encontrassem na casa da senhora $X$ para a reunião de fundação da associação, que eu presenciei. Eu me perguntei o que estava em jogo no dinamismo das atitudes contemporâneas sobre os traumas e desaparecimentos de mais de meio século, com a sensação de que estava se reinstaurando uma possibilidade criativa de elaboração dos lutos e da perda como autorizado ou legitimado pelo projeto de pesquisa nos arquivos e de transmissão.

Rapidamente me pareceu que o que estava em jogo era um caminho complexo no qual se trata de numerosos elementos problemáticos, dos quais se podem enumerar alguns:

- A filiação e a reinscrição em uma cadeia genealógica;

\footnotetext{
${ }^{3}$ As crianças escondidas e perseguidas na França devem sua sobrevivência aos esforços desesperados de seus pais ou das organizações de salvamento das crianças judias para colocá-las a salvo. Elas foram o mais frequentemente confiadas a instituições religiosas cristãs ou a famílias que as acolheram. 0 termo "crianças escondidas" não se torna um traço identitário senão recentemente, permitindo doravante a centenas de milhares de pessoas de todo o mundo se reconhecerem em uma experiência singular. A associação das "Crianças escondidas" foi criada sobretudo após o primeiro encontro internacional das crianças escondidas, que aconteceu em Nova Iorque em 1991.
} 
- Um dever de enterrar, injunção inevitável e paradoxal, sem corpo, sem ritos e sem sepultura;

- A questão do luto diferido;

- Os processos autoterapêuticos para reelaborar uma infância destruída;

- A gestão da culpa associada à sobrevivência em uma situação de genocídio; - Os lugares de pais confrontados com uma necessidade de transmissão da história familiar e do traumatismo coletivo histórico em relações difíceis com seus filhos; - Um apetite insaciável por conhecimento sobre os pais deportados, que os levará a ir visitar os arquivos disponíveis.

Desde a criação da Associação pela memória do Comboio Y, a questão da pesquisa imperiosa em arquivos como um compartilhamento de arquivos familiares, etc., está no coração dos projetos da associação. Neste apetite que vai além de um dever de piedade filial e de trabalho de luto, tratou-se também, através da pesquisa arquivística, sob diferentes formas, sobre o Comboio $\mathrm{Y}$, de construir um suporte para o conhecimento e para a transmissão.

Freud falou de uma pulsão epistemofílica, pulsão de saber, pulsão de conhecimento a partir da libido. Além de Freud, para o psicanalista René Kaës, o apetite por arquivo é certamente inseparável da imperiosa necessidade de saber para transmitir: “(...) um fenômeno que poderia ser descrito como uma urgência ou como uma espécie de impulso para transmitir sob o efeito de um imperativo psíquico incoercível (...)" (KAES, 1993, p. 8).

Pois, como escreve Régine Waintrater (2003, p. 19): "Todo genocídio é uma catástrofe da filiação: é a aniquilação simultânea de três gerações, aquelas que são necessárias ao estabelecimento de toda filiação, para permitir que cada um possa se situar em um conjunto de sujeitos e se reconhecer como tendo sido gerado e como capaz de gerar".

Parece-me que é preciso ver a demanda por arquivo como um processo de historicização. 
Não separarei a história e a historicização, e como escreve Annette Wievorka: “A história é também uma das modalidades do trabalho de luto, tentando operar - com dificuldades de todas as ordens -, a indispensável separação dos vivos e dos mortos." WIEVORKA (2005, p. 280).

O procedimento de historicização (ENRIQUEZ, 1988) e sua necessidade de arquivos se torna uma necessidade imperiosa, como destaca também François Maspéro, cujo pai, deportado político, morreu em Buchenwald: “Estranhamente, quanto mais eu me afastei no tempo, mais minha preocupação de ver claramente o que foi a vida de meu pai no campo se definiu" (2002, p. 29).

Foi uma paixão pelos arquivos que se apoderou desses filhos de deportados que participam da associação do Comboio Y. Gérard faz um percurso complexo, que evolui há décadas em torno da deportação de seu pai, que retornou dos campos e morreu em seguida. No início dos anos 1990, ele participa durante vários anos de um "grupo de falas" de filhos de sobreviventes da Shoah, que Ihe deixa uma impressão tênue de nãoacabamento, mas o reconecta enfim a uma forma de identidade. Um estalo significativo Ihe acontece quando ele participa de uma comemoração nos campos de internamento de Loiret: “Fui à cerimônia de Pithiviers/Beaune-La-Rolande, completamente por acaso. Nós nos encontramos em um pequeno grupo e a ideia que eu tive de ir fazer buscas nos arquivos lhes interessou. Tornou-se uma espécie de revelação. Fomos aos Arquivos Nacionais ingenuamente. A pessoa que me interessava era meu pai, que eu conheci e que morreu. Foi no momento em que se falava muito das espoliações, da comissão Drai e Mattéoli ${ }^{4}$. Procuro meu pai no microfilme, e aparece toda a família dele, coisa que eu absolutamente não esperava. São as fichas de Beaune-La-Rolande, de Drancy, do Departamento de Polícia, etc. Isto me marca sacramente, pois eu não conhecia a história do meu pai. Eu sabia vagamente que ele estava em Beaune-La-Rolande e fora deportado para Birkenau. Sei que meus avós foram deportados também, mas em que circunstâncias?

\footnotetext{
${ }^{4}$ Comissões de indenização das espoliações financeiras realizadas contra os judeus durante a Ocupação, implementadas pelos governos Juppé e Jospin. Uma delas, a missão de estudos sobre a espoliação dos judeus da França, instituída em 1997, depois a comissão de indenização das vítimas das espoliações em razão das legislações antissemitas durante a Ocupação.
} 
É a passagem do abstrato para o concreto. De repente, tens diante dos olhos elementos materiais que descrevem a trajetória de tua família."

O acesso e as pesquisas nos arquivos constituem uma reviravolta considerável na representação que Gerard tem de sua família e no dinamismo pessoal e interpessoal que se desencadeia: "Coloco-me a vasculhar intensamente os arquivos e chego a reconstituir não somente uma árvore genealógica, mas as relações entre várias pessoas. Resta-me muito pouco de família. Reconstituí uma grande parte da trajetória da família do meu pai a partir do momento em que ele chegou à França, assim como em relação à família da minha mãe. Aconteceu-me uma grande quantidade de coisas através dos arquivos, através dos encontros de pessoas que tinham conhecido a família do meu pai antes da guerra. Da ausência de história familiar, encontro-me com uma história familiar dolorosa."

A pesquisa de Gérard torna-se objeto de uma verdadeira paixão e uma revelação que dá um sentido ao seu percurso: “Desde que eu coloquei o nariz lá, me senti dominado por aquilo. É algo que me domina, é o que eu devo fazer. Não unicamente por mim, acontece que eu tenho filhos pequenos, e isso parece que tem uma relação com eles. Quando eu olho o meu percurso, dou-me conta de que toda a minha vida girou em torno do que se passou durante a segunda guerra mundial, os campos, sem que eu percebesse. Nasci em 1948. Meu percurso foi determinado pelos campos. Meu pai não falava senão em termos de campos. Nada era dito diretamente por meu pai, o que eu pude saber, era quando ele falava com outras pessoas. (...) Enquanto adulto, era também impossível de falar disso com meu pai, do seu destino e do meu. Todas as questões que eu me faço, ele poderia ter-me respondido há dez anos, eu poderia ter-lhe feito as perguntas, ele teria respondido. Acontece que isso não foi feito (FRESCO, 1981) ${ }^{5}$. Não me culpo por isso. Sou filho único. Não tive uma relação simples, meu pai não era um cara flexível, nem se prestava muito à escuta. Ele se fechava sem explicação.” Ou Martine: “Resumir a vida de meu pai em algumas linhas, pois eu não sei nada mais sobre ele, é

\footnotetext{
${ }^{5}$ Nadine Fresco (1981) descreve o domínio do silêncio ou as revelações ensurdecedoras dirigidas à primeira geração nascida após a Shoah: a autora nos diz: “(...) desde a infância, o silêncio era absoluto demais, para que a comunicação fosse totalmente uma surpresa." (1981: 206) Para outros, é um mutismo total sobre um mundo de dores e sofrimentos ocultos e "dramas de acesso proibido" (idem: 2008), mas cujos indícios múltiplos destacam a amplitude dos lutos impossíveis. A autora nos diz que a esses adolescentes era transmitida a ferida, mas não a memória.
} 
muito doloroso, mas, uma vez que estiver feito, eu disse comigo, ele existirá para os descendentes. Temos muito pouca herança, uma foto desfocada, quase nada. Nesta pesquisa, encontrei rastros nos arquivos. Meu pai fez o máximo, ele se engajou.”

É preciso também pensar a demanda arquivística como aquela que se dirige aos Lugares de memória e principalmente às viagens a Auschwitz como na caminhada de Ernest, que se tornou historiador após a sua aposentadoria. $O$ adolescente Ernest adoece em junho de 1942 e parte para uma casa de saúde, o que lhe permite escapar da pilhagem de Vel-d'hiv de julho de 42. Ele nos diz: “Quando me casei, nos primeiros anos, no meu sono, eu começava a gritar, eu buscava o meu pai e ele não estava lá, ou eu estava bravo com ele, em pesadelos terríveis nos quais eu me punha a gritar, e minha mulher me acalmava. Não foi senão em 1981, no $39^{\circ}$ aniversário da deportação, que o Rabino Farhi, com a sua associação dos judeus liberais, decidiu fazer uma peregrinação a Auschwitz. Fui com a minha mulher, e foi nesse momento que eu tive o meu luto. Quando voltei, não tive mais pesadelos, tinha acabado. O caminho do meu pensamento se fez da noite para o dia, quando encontrei o lugar, eu conhecia as condições, encontrei depois de 50 anos o meu equilíbrio em relação ao meu pai. Tive o luto por ele, estava acabado, e depois, durante toda a minha vida, me interessei pelo judaísmo." Com uma tese em história e várias obras que são autoridade sobre o judaísmo da Europa oriental antes da guerra.

É preciso compreender a demanda arquivística como um fenômeno complexo, com a conjunção de diferentes aspectos: um novo reconhecimento da Shoah e da colaboração na França através das leis e pensões reparadoras, mas que exige que se tragam provas sobre as espoliações e portanto requer utilizar os documentos dos arquivos. A constituição de novas associações a partir do reconhecimento da existência de novos grupos, como o das crianças escondidas, cuja primeira reunião internacional em 1991 em Nova lorque vai criar várias associações pelo mundo e iniciativas individuais.

\section{Como compreender esses fenômenos?}

Proporei alguns caminhos para a reflexão e para a inter-relação de nossas diferentes disciplinas. Encontramos por um lado, entre outros, como metáfora para 
compreender esses fenômenos, os processos de reinscrição como uma forma de recusa de fazer da Shoah o único acontecimento fundador ancestralizado como ponto de partida da linhagem. Isto vai no sentido do conceito de "reinscrição" e de transmissão de uma memória da experiência anterior ao genocídio, desenvolvido de um ponto de vista antropológico por Lemée et Galay (2003).

O genocídio não era somente um extermínio, mas uma tentativa de apagamento, “eles não terão existido". Igualmente, este aspecto, tendo às vezes a compulsão de encontrar arquivos, está à altura desta atitude, combater uma tentativa de des-existência, a negação daquilo que terá existido, e daquilo que pode advir: a descendência e a cultura. Evocamos as hipóteses complexas, mas frutíferas de Bergès sobre a "negação do futuro anterior" a propósito do luto e da depressão na criança (1996), que se pode eventualmente ampliar para o nosso propósito. Não é “já não existe”, mas "não terá existido".

Podemos voltar a Derrida e à sua crítica do historiador inglês Joseph Yerushalmi, que não aceitou o roteiro de Freud em seu Moisés (1939). A tese de Freud à imagem de Totem e Tabu (1912) é que Moisés, o egípcio, é assassinado pelos hebreus no limiar da terra prometida e que este assassínio, a exemplo do do pai da tribo, é recalcado (totalmente esquecido ou excluído). Derrida lembra o lugar central do recalcamento na obra freudiana e a observação de Yerushalmi (1984): se este assassínio tivesse acontecido, a Torá (bíblia hebraica), que é prolixa nesses assuntos, teria mencionado. Derrida volta ao recalcamento como modo de arquivamento: "Simplesmente, acrescenta ele, os textos deste arquivo não são legíveis pela 'história ordinária', e eis todo o interesse da psicanálise, se ela tem algum."

Este comentário é importante também em outra direção, que é a transmissão transgeracional do traumatismo. Como se a demanda imperiosa por arquivos também estivesse lá para dar um sentido ou fazer sair do recalcamento esta transmissão inconsciente do traumatismo da geração precedente. Assim, o conceito de pós-memória, desenvolvido nos EUA por Marianne Hirsch, pode ser útil. Marianne Hirsh propõe a noção de "pós-memória" para designar este eco indireto de um acontecimento traumático, que não é mediado por lembranças, mas por um investimento imaginário e uma iniciativa 
criadora (HIRSCH, 1997). É assim como a construção de uma memória quase pessoal sobre acontecimentos que não foram vivenciados, ou seja, o encarregar-se, pelos descendentes, de um passado traumático que eles herdam pessoalmente. É um fenômeno que Marianne Hirsh vai estudar particularmente a partir do Livro Maus, de Art Spiegelman (1986), sobre a experiência da Shoah de seu pai, deportado e sobrevivente, Vladek. Este livro, na forma de quadrinhos, não é um exercício de estilo; parece impor-se a Spiegelman a partir da sua relação muito difícil com este pai que voltou da deportação; mas também a onipresença de seu irmão morto durante a guerra e o suicídio de sua mãe. Os filhos e os netos de deportados investem em narrativas de seus pais para alimentar suas próprias memórias e inscrever-se numa trajetória coletiva. As pesquisas nos arquivos são um dos pilares desta construção da memória.

\section{Conclusões}

Parece-nos que é preciso compreender a demanda por arquivos como um fenômeno complexo que só pode ser apreendido na transversalidade de diferentes disciplinas, e a psicologia, a partir de um trabalho de campo, pode oferecer uma modesta contribuição.

\section{Referências}

BERGES, Jean. Les états dépressifs de l'enfant. Conférence de l'hôpital Sainte Anne (conférence dactylographiée non publiée, 1996).

BOCHURBERG, Claude. Entretien avec Serge Klarsfeld. Paris: Stock, 1997.

DERRIDA, Jacques. Conférence prononcée le 5 juin 1994 à Londres lors d'un colloque international : Memory: The Question of Archives. Le texte est daté du 22-28 mai 1994.

ENRIQUEZ, Micheline. L'enveloppe de mémoire et ses trous. Topique 42, p.185-205, 1988. 
FREUD, Sigmund. Totem et tabou. Paris: Payot, 1968.

. Moise et le monotheisme. Gallimard: Paris, 1939/1967.

FRESCO, Nadine. La diaspora des cendres, Nouvelle Revue de Psychanalyse, Paris, l’Emprise, 24, p. 205-220, 1981.

GANDINI, Jean-Jacques. Le procès Papon. Paris: Librio, 1999.

HIRSH, Marianne. The Generation of Postmemory, Poetics Today, Durham, 29, 1, p. 103128, 2008.

. Family Pictures: Maus, Mourning and Post-Memory, Discourse, 15, 2, p. 3-29, 1992.

KAES, René.Transmission de la vie psychique entre generations. Paris: Dunod, 1993.

KLARSFELD, Serge. Le Mémorial de la déportation des Juifs de France. Paris: FFDJDF, 1978.

LEMEE, Carole.; GALAY, Daniel. L'Après-Shoah: des traumas aux processus de réinscription, Face à Face, 5, 2003.

MASPERO, François. Les abeilles et la guêpe. Paris: Seuil, 2002.

LEVI, Primo. Si c'est un home. Paris: Julliard, 1987.

MOUCHENIK, Yoram. De la disparition au deuil chez les orphelins de la Shoah, L'autre, 5, 1, p.129-141, 2004.

. Ce n'est qu'un nom sur une liste, mais c'est mon cimetière, Grenoble: La Pensée Sauvage, 2006.

SPIEGELMAN, Art. Maus : Un survivant raconte. 1986

WAINTRATER, R. Sortir du génocide. Témoignage et survivance. Paris: Petite bibliothèque Payot, 2011.

WIEVORKA, Annette. Auschwitz, 60 ans après, Paris: Robert Laffont, 2005.

YERUSHALMI, Yosef.; HAYIM, Zakhor. Histoire juive et mémoire juive. Paris: La découverte, 1984. 
